\title{
[trabahonecessário
}

issn: $1808-799 \mathrm{X}$

ano 3 número $3-2005$

\section{FLIP 2: SOB A MÁSCARA DO FETICHISMO DA MERCADORIA SOBRE A SEGUNDA EDIÇÃO DA FESTA LITERÁRIA DE PARATY}

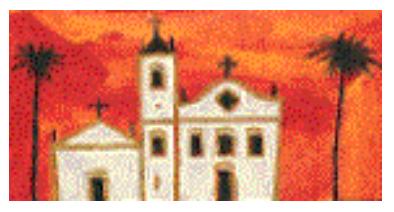

Kênia Miranda[1]

"O artista na época do capitalismo encontrou-se numa situação muito peculiar. O Rei Midas transformava tudo o que tocava em ouro: o capitalismo transformou tudo em mercadoria".

(FISCHER, 1984, p.59)

\section{Introdução}

A 2aㅗ Festa Literária de Paraty (FLIP) ocorreu entre os dias 7 e 11 de julho de 2004 no sul fluminense, numa nostálgica cidade escoadora das riquezas do café e do ouro, do período colonial. Mesmo com a decadência do ciclo do ouro e do café, a cidade de Paraty* conservou parcialmente sua arquitetura original conquistando o título de monumento histórico e nacional.

A política de turismo dos setores público e privado de Paraty, que tem nessa atividade sua principal atividade econômica, é voltada para promoção de festivais os mais variados durante todo o ano. Porém, nenhum outro evento, teve ou tem a dimensão e a publicidade da Flip.

O evento comercial-literário, planejado dentro dos moldes do tradicional festival literário e artístico de Hay-on-Wye, no País de Gales, contou, em sua programação oficial, com 
palestras de escritores brasileiros e estrangeiros, debates e atividades culturais como mostra de filmes, shows musicais e apresentações teatrais. E como não poderia deixar de ser, o centro histórico de Paraty foi tomado por tendas de editoras financiadoras da Festa que promoviam lançamentos, propagandas e vendas de livros. A Festa cresceu em relação à sua primeira edição, seja com relação ao número de escritores e editoras estrangeiras, seja no número de visitantes (cerca de 12 mil), além do acréscimo de mais um dia à programação.

A $2^{\text {a }}$ edição da FLIP, que sofreu diversas alterações, a partir do título, passando de Festival a Festa, não pode ser analisada circunscrita à sua aparência, uma vez que é expressão de mudanças significativas nas esferas econômica e cultural ocorridas nas últimas décadas.

O evento, amplamente divulgado pela mídia, ofereceu uma fértil experiência com a indústria cultural capitalista, incitando a uma análise da cultura através do método da economia política. O presente ensaio, realizado a partir deste evento, tem como suporte as reportagens produzidas pelo jornal O Globo e Jornal do Brasil, durante os meses de junho e julho de 2004, nos mais diferentes cadernos e seções.

O fenômeno sócio-cultural em questão ocorre no período chamado de pós-modernismo, definido por Jameson como:

um conceito periodizante, cuja função é correlacionar a emergência de novos aspectos formais da cultura com a emergência de um novo tipo de vida social e com uma nova ordem econômica - aquilo que muitas vezes se chama, eufemisticamente, de modernização, sociedade pós-industrial ou de consumo, sociedade da mídia ou dos espetáculos, ou capitalismo multinacional. (1996, p.27)

É inegável que a contemporaneidade nos oferece características peculiares no contexto da pós-modernidade[2]. E, portanto, as análises científicas devem estar atentas a tais particularidades. Contudo, não faremos uma análise apologética da mudança de paradigmas. Entendemos que as variações nas formas em que o capital se apresenta não são capazes de abolir sua dicotomia estrutural, qual seja, a apartação entre a produção e o seu controle. É nessa linha que Jameson e outros teóricos marxistas críticos da pósmodernidade desenvolvem suas análises, sendo nesse campo teórico que pretendemos realizar tal exercício de compreensão da FLIP.

\section{Do Flip à Flip: a lógica cultural do capitalismo tardio}

Ao tratar da problemática cultural no pós-modernismo, Fredric Jameson, destaca como seus elementos estruturantes o discurso do Fim da História e, por conseguinte, das classes sociais, o ataque às metanarrativas modernistas, o desmonte da racionalidade, a inviabilidade de sínteses totalizantes, enfim, um discurso que utiliza a ideologia para dar cabo dela própria.

A lógica cultural do capitalismo tardio frente à sociedade do consumo está organizada sobre uma tríade marcante - "pastiche", "morte do sujeito" e "nostalgia" - que permite "sentirmos a especificidade da experiência pós-modernista do espaço e do tempo" (JAMESON, 
1996).

O "pastiche" toma a cena, como máscara estilística da reiteração - reprodução e sobreposição de estilos, imitação esvaziada de conteúdo - condizente com a "nostalgia", essa tomada como resgate de um passado nada ameaçador e instigante que ofusca a relação humana com o seu presente histórico. Velando, dessa forma, o sujeito social que, mutilado de sua autoria, criatividade e potência revolucionária, permite-se mover no mundo deixando-o tal e qual. É esse último sintoma pós-modernista que Jameson denomina de "morte do sujeito".

Este trabalho não tem a pretensão de realizar uma análise das obras literárias em evidência no evento, mas, de uma maneira geral, um breve olhar sobre o conjunto da produção exposta e vendida no evento sugere que as obras são exemplos do pensamento cultural hegemônico exposto acima. Com efeito, as obras versam sobre histórias cotidianas cuja subjetividade tem caráter meramente individualista, ocorrem em espaços / tempos efêmeros, permeadas por idéias fugidias, características das representações estéticas da pós-modernidade.

As temáticas variadas e estanques tratadas nos debates deram o contorno fragmentador do evento indicando o que vem sendo comercializado no mercado literário internacional, cuja qualidade pode ser considerada, na maioria dos casos, discutível, ou pelo menos, pós-moderna celebratória.

No último dia da Festa Literária de Paraty, 11 de julho, o "jornalista" Agamenon Mendes Pedreira anunciou em sua coluna dominical de humor do jornal O Globo: "Flip! Flip! Nheco! Nheco!" Para a coluna, em que o grupo "Casseta e Planeta" utiliza o pseudônimo de Agamenon, os melhores escritores ingleses e americanos pós-modernos foram definidos como "hooligans literários" que "quebravam dogmas, conceitos estéticos e paradigmas". Brincadeiras à parte, a definição parece bastante adequada à hegemonia literária e cultural contemporânea.

De fato, a FLIP precisa ser compreendida no movimento da totalidade social em direção às particularidades, como síntese dessas múltiplas determinações.

A sociedade contemporânea sofre, portanto, a denominação de etapa pós-moderna, definida acima e determinada pela globalização da economia ou, em outros termos, pela mundialização do capital. No interior do movimento do sistema capitalista há um processo dialético e contraditório de reestruturação com fins de reprodução ampliada do capital.

A última transição no padrão de acumulação capitalista (que estamos vivendo), do fordismo à acumulação flexível (Harvey, 1992), é um período de transformação no mundo do trabalho e, em certa medida, na superfície das relações sociais, que abrem novas possibilidades de realização do processo de acumulação de riquezas em um território cada vez mais abrangente. Segundo REIS:

Há pouco mais de três décadas o mundo assiste com um misto de incredulidade e impotência a montagem e a consolidação dos novos impérios econômicos transnacionais. Tendo a frente os meios de comunicação e a indústria de entretenimento, e como suporte toda sorte de conglomerados financeiros, industriais e organizações supranacionais, como o sistema de telefonia, redes de televisão, rádio, 
redes eletrônicas e satélites. (2002, p.4) Com a reestruturação do padrão produtivo ocorrido a partir da década de 1970, a esfera cultural foi definitivamente incorporada à estrutura econômica da sociedade, como mercadoria de grande potencial expansionista do mercado capitalista, possível graças à utilização do avanço tecnológico e científico pelos impérios econômicos transnacionais de que trata REIS.

Em outras palavras, a cultura assumiu formas comerciais, produtora de mercadorias, sendo isso feito mediante a absorção das diversas formas de produção imateriais e da sua oferta em escala planetária como bem de consumo cultural (Hardt e Negri apud REIS, 2002).

A lógica cultural do capitalismo tardio (JAMESON, 1996), permeada pela estetização da vida social produzida pela visão de mundo burguesa, está subsumida ao quadro de dominação político-econômica dos países centrais do sistema capitalista, promovendo um encurtamento entre a estrutura material e superestrutura espiritual da sociedade. Ou seja, através das indústrias de entretenimento a cultura foi transformada em produção material, chegando a representar, nos Estados Unidos, um império que corresponde a segunda maior fonte de acumulação do país na atualidade.

O capitalismo internacional ao esbarrar com o esgotamento de suas possibilidades expansionistas, lançou mão de estratégias almejando novos mercados, seja dentro dos próprios países centrais, seja dentro dos países da periferia do sistema, através da criação de novas mercadorias. Entre essas novas mercadorias destaca-se a cultura, pois segundo a análise marxiana, a mercadoria pode satisfazer ou simular a satisfação de necessidades do corpo ou da alma. Uma "mercadoria cultural", em grande parte de caráter imaterial, ou pelo menos de curto ciclo de vida, para ser consumida deve, de maneira associada, consumir as inovações tecnológicas do setor de comunicação. Dessa forma, abre-se espaço para o consumo de novos produtos. Embora a criação de novas necessidades não seja algo inaugurado pelo capitalismo tardio, a indústria de entretenimento é expressão de seu esforço contínuo a esse fim.

Nesse contexto, a FLIP pode ser entendida como mais uma faceta da expansão da indústria cultural de marca pós-moderna em direção aos países da periferia do sistema capitalista. Assim, o primeiro FLIP (Festival Literário Internacional de Paraty) foi organizado a partir dos interesses das grandes empresas editoriais internacionais com vistas a examinar o mercado brasileiro, seja para lançar seus autores, seja para levar novos autores aos seus mercados.

As significativas mudanças na $2^{\underline{a}}$ edição do evento, com alto investimento de empresas nacionais e grande participação de autores brasileiros, podem ser compreendidas como uma ação defensiva das editoras nacionais, frente à possibilidade de serem absorvidas pelas grandes editoras internacionais, a exemplo do que vem ocorrendo no lucrativo mercado editorial de livros didáticos. Essa atitude defensiva é bastante compreensível do ponto de vista do capital brasileiro, uma vez que a concorrência intercapitalista leva 
necessariamente a concentrar a propriedade dos meios de produção em monopólios, sendo expressão de uma tendência interna ao movimento do capital: a centralização. Ou seja, se numa primeira oportunidade, o mercado internacional se lançou como interessado no mercado de exportação a partir do oportuno mercado brasileiro, num segundo momento, a indústria editorial nacional, associada ao capital financeiro local, resolveu resguardar seu mercado. A tentativa de impor-se como o legítimo representante e tutor dos "interesses nacionais" do mercado editorial, fez mudar, substancialmente, o perfil dos financiadores do evento. Fato que analisaremos na seção a seguir.

\section{"Os intérpretes da alma da mercadoria": sobre organizadores, editoras e}

\section{financiadores}

Os mais importantes financiadores do evento foram as editoras Companhia das Letras e Record, além do terceiro maior banco do país: o Unibanco. Reiterando a análise acima de que houve uma refutação das empresas nacionais ao interesse de entrada no mercado brasileiro pelas editoras estrangeiras.

A fundadora do evento é Liz Calder, sócia da grande editora inglesa Bloomsbury (responsável pela publicação do best seller da saga Harry Potter), presidente da FLIP e da ONG[3] Casa Azul, criada em 2002 para responder juridicamente pela festa literária. A organizadora de nacionalidade inglesa, incitada pelo sucesso do festival de Hay-on-Wye [4], no País de Gales, contou, além de sua própria experiência na organização desse festival e na Inglaterra, com o apoio do diretor do festival galês, Peter Florence. Liz Calder vinha buscando apoio para realizar o festival em Paraty há quase duas décadas, portanto, só encontrou condições de concretizá-lo na atual configuração do mercado editorial internacional.

À entrada do maior patrocinador do festival, Unibanco, soma-se a de um patrocinador até então inédito, a Biblioteca Nacional (BN), portanto, com financiamento público direto. A BN custeou a vinda de agentes literários estrangeiros, além da tradução de capítulos de livros dos escritores brasileiros que compuseram um catálogo às editoras internacionais, principalmente dirigido às espanholas, que têm se mostrado bastante interessadas na aquisição de editoras brasileiras. A BN "investiu" em tais atividades cerca de 2 milhões de reais no evento (Jornal do Brasil. Idéias. 03/07/2004, p.1).

A Festa recebeu da mídia[5] a manchete de divulgadora da literatura no país, ratificado pelo discurso de Liz Calder, organizadora do evento, alegando que a grande tenda montada em frente à Igreja Matriz teria democratizado o acesso do público à literatura. Porém, tal democratização ocorreu num espaço de exacerbação da lei do valor, onde o custo diário de permanência na cidade histórica não foi o habitual e que, conseqüentemente, destinou-se a uma parcela bastante restrita daqueles que fazem turismo[6]. Todas as atividades de palestras e debates tiveram ingressos vendidos com antecedência e, conforme noticiado pelo jornal O Globo (O Globo. Prosa \& Verso, 03/07/2004), os ingressos vendidos para o debate entre Chico Buarque e Paul Auster 
esgotaram-se no terceiro comprador da fila.

A fragilidade do argumento de democratização do acesso pode ser facilmente avaliada pelos números que ofereceram a estrutura física do evento. A tenda dos autores, que comportava 550 pessoas, abrigava as palestras e a tenda da Matriz, com capacidade de 1.100 pessoas, que assistiram aos debates por telão e tradução simultânea. Cabe talvez destacar, que na edição anterior, os debates foram realizados na Casa de Cultura, apta a receber 200 visitantes. Dessa forma, os próprios Paratyenses ficaram excluídos das atividades principais do evento, assim como a única livraria da cidade (Nova Paraty), que não sendo informada da licitação, disputada por editoras do Rio de Janeiro e São Paulo, ficou de fora da FLIP.

As celebridades do evento são consideradas pelo mercado os melhores - leia-se: os mais vendidos - escritores da literatura inglesa e americana e estão sendo lançados no Brasil. Dentre eles podemos destacar os trazidos pelas editoras inglesas: Martin Amis e lan McEwan, responsáveis pelo desenho pós-moderno da literatura britânica. A editora americana trouxe Paul Auster, considerado pelos jornais brasileiros "o maior autor do mundo na atualidade", e Jeffrey Eugenides. Outras editoras estavam presentes através de seus autores: Colm Tóibín, irlandês, Agualusa, angolano, Pierre Michon, francês, e Lídia Jorge, portuguesa. À editora Bloomsbury pertencem: Chico Buarque e Milton Hatoum, além de Siri (sr-a Auster) que já trabalhou com Liz Calder.

A FLIP, em sua $2^{a}$ edição, homenageou Guimarães Rosa, cuja obra, aliás, tem interessado editoras internacionais, que marcaram presença no evento. Além de G. Rosa, as editoras estrangeiras têm se mostrado interessadas em publicar autores brasileiros contemporâneos que têm grande público, como Luís Fernando Veríssimo. Os demais autores que participaram da programação oficial foram: Ziraldo, Caetano Veloso, Lygia Fagundes Telles, Moacyr Scliar, Sérgio SantAnna, Milton Hatoum, além dos novatos Adriana Lisboa, Joca Terron, Marcelino Freire e Daniel Galera. João Ubaldo Ribeiro, que seria mediador de uma das mesas, retirou sua participação alegando discriminação por parte da organização por não ser um autor da Cia das Letras.

Liz Calder explicou ao jornal O Globo a importância do evento para os editores, chamando atenção para o fato de, na Inglaterra, os livros serem lançados na época dos festivais, já que sem eles o espaço na mídia seria muito restrito para os autores. Podemos identificar no seguinte trecho da referida entrevista o caráter estritamente comercial[7] do evento: Eu sou editora também, quero vender mais livros. Esses festivais literários são muito bons para todos os editores, porque os livros vendem mais nesses dias, saem nos jornais, Têm muito mais publicidade dos autores. (O Globo, Prosa \&Verso, 03/07/04).

Com efeito, o papel da publicidade é o de construir o desejo por uma determinada mercadoria, nesse caso descrito por Liz, a produção literária de massa contemporânea. No processo de fetichização, a economia cria necessidades, novidades, torna futilidades essencialidades. A produção de mercadorias na sociedade capitalista produz determinadas relações sociais, que são em geral, ocultadas pelo processo de fetichização 
[8] da mercadoria, isso envolve tanto uma ampliação da esfera do consumo como uma deterioração potencial de sua qualidade e implica, em qualquer caso, uma crescente manipulação do consumidor pelas empresas capitalistas nas esferas da produção, da distribuição e da publicidade. (BOTTOMORE, 2001, p.79).

Concomitante à propaganda de seu produto, os editores internacionais buscam avidamente conhecer a produção literária brasileira a fim de comercializá-la no mercado internacional. Nesse sentido cabe destacar as palavras da editora americana Nan Talese:

"caminhava atenta em busca de jovens autores que têm potencial de atrair leitores americanos [...] prefiro publicar autores jovens para acompanhar dede o inicio a evolução da obra" (O GLOBO. Prosa \& Verso: 17/07/2004, p.5).

Com a mesma intencionalidade, o editor Morgan Entrekin, da Grove/Atlantic, que lançará Budapeste, novo livro de Chico Buarque, nos EUA, saiu de Paraty analisando inúmeros projetos editoriais.

"Face às mudanças que a FLIP vem sofrendo e projetos que vem abarcando, podemos destacar o germe de uma relação que se estreita: literatura-cinema".

Tendo em vista a dimensão que o cinema nacional vem conquistando, Liz Calder declara:

"Para 2005 a idéia é criar um diálogo entre literatura e cinema, para debater com autores que têm obras adaptadas ou que escreveram roteiros de filmes", uma vez que tal mercado começa a se expandir no país.

Coadunada a essa proposta, na $2^{-a}$ FLIP, esteve presente Jeffrey Eugenides, que teve dois de seus livros transformados em filmes, além de um terceiro que está sendo escrito com a mesma finalidade. Também representando a área, Cacá Diegues foi mediador de debate na FLIP do debate de Caetano e Agualusa, embora seu livro - O que é ser um diretor de cinema (Editora Record) - não tenha sido lançado na FLIP.

O cinema, como carro chefe da indústria cultural mundial, vem cada vez mais estreitando seus laços com a literatura, direcionando a produção dessa última, até mesmo a partir de obras encomendadas, para essa grande fatia do mercado cultural. A relação literaturacinema é tratada por autores participantes da FLIP como um novo estilo literário. As fronteiras de suas especificidades se tornaram tênues e no lugar de uma relação de colaboração mútua entre literatura e cinema se sobrepõe uma relação utilitarista. Em outras palavras, a obra já é produzida para simular ou tornar-se um filme como já anuncia Miguel Souza Tavares ao dizer que seu livro Equador (Editora Nova Fronteira) é um "filme descrito", pois essa é a melhor maneira de prender o leitor. (O GLOBO, 08/07/2004, p.3).

Ao que tudo indica, o casamento entre cinema e literatura deverá ser o principal atrativo das vendas na $3^{\text {a }}$ FLIP.

\section{Ensaiando conclusões}

O novo padrão de acumulação aproximou a esfera cultural da produção de mercadorias. Em busca de um mercado cada vez mais amplo, o capital tornou inerte o caráter humanizador da arte e tenta, a todo momento, torná-la mero entretenimento. Tais transformações culturais induzidas pelas mudanças no padrão de acumulação têm sido 
objeto de análise de marxistas como Jameson, Eagleton, Harvey e Anderson e, diante desse quadro conjuntural, apontam para a supressão da barreira entre a dimensão econômica e cultural da sociedade.

Vivemos em um período em que a crítica radical à sociedade capitalista já não ecoa e os desejos humanos são coisificados, ganhando destaque na sociedade do espetáculo. Dessa forma, os negócios celebrados na Festa Internacional de Paraty, visam promover um determinado gênero de consumo e a conseqüente expansão de negócios no setor da literatura, trazendo no seu bojo dois objetivos principais. Com relação a seu objetivo mais totalizante, a FLIP busca fazer uma mediação entre o mercado editorial estrangeiro e as grandes editoras brasileiras. E, com relação a seus aspectos locais, o evento parece desejar capturar uma parcela do mercado turístico intelectualizado para a cidade de Paraty.

O evento em análise deve ser entendido tão somente como mais uma forma de reprodução ampliada do capital e não como realização desinteressada.

Recorrentemente, os discursos de inúmeros entrevistados pela grande imprensa, alguns desses citados neste estudo, apontavam para o quão acertado foi o tamanho da Festa e, sendo assim, jamais poderia perder seu clima intimista. Numa sociedade cindida em que uma minoria pode dedicar-se à fruição de bens culturais e um grande contingente de trabalhadores não tem sequer satisfeitas suas necessidades mínimas, a burguesia também expropria da classe trabalhadora determinados espaços sociais, culturais e geográficos.

Em Paraty, o livro trocou sua tradicional valia, a forma se sobrepôs ao conteúdo, os autores ganharam status de atores globais, celebridades, e, uma fatia da burguesia, disse representar o público leitor deste país.

A FLIP é, na verdade, tão somente um encontro de negócios que mede forças e disputa a configuração do mercado editorial, a literatura não é pensada em seu valor de uso, mas no seu valor de troca em expansão.

A Festa Literária Internacional de Paraty, fenômeno transcorrido no plano da circulação das mercadorias, oculta as relações sociais, no caso entre editores/ autores/ leitores, transformando-as em relações coisificadas, que - sob a máscara do fetichismo da mercadoria - ocultam as relações essenciais existentes no processo de produção da vida.

\section{Referências Bibliográficas}

BOTTOMORE, Tom. (org.) Dicionário do pensamento marxista. Rio de Janeiro: Jorge Zahar Ed., 2001.

EAGLETON, Terry. A ideologia da estética. Rio de Janeiro: Jorge Zahar, 1993.

FISCHER, Ernst. A necessidade da arte. Rio de Janeiro: Zahar, 1984.

HARVEY, David. Condição pós-moderna: uma pesquisa sobre as origens da mudança cultural. São Paulo: Loyola, 1992

JAMESON, Frederic. Pós-modernismo: A lógica cultural do capitalismo tardio. São Paulo: 
Ática, 1996.

"Pós-modernismo e sociedade de consumo". In: KAPPLAN, Ann. O mal-estar no pós-modernismo: Teorias Práticas. Rio de Janeiro: Jorge Zahar, 1990.

MARX, Karl. O Capital. (14르 ed.). Rio de Janeiro: Bertrand Brasil, 1994.

REIS, Ronaldo Rosas. "Trabalho e conhecimento estético". In Revista Trabalho, Educação

e Saúde, volume 2, número 2. Rio de Janeiro: Escola Politécnica de Saúde Joaquim

Venâncio, Fundação Oswaldo Cruz, 2004.

. "Conformismo pós-moderno e nostalgia moderna". In: Revista da Universidade

Federal Rural. Série Ciências Humanas. Seropédica, RJ: pp. 165-179. 2000.

www.uff.br/mestcii/rep. 2001

A formação do Imaginário Estético-Cultural no Capitalismo. Niterói: UFF/

Faculdade de Educação (mimeo), 2002.

[1] Mestranda em Educação no campo Trabalho e Educação do Programa de Pós-Graduação em Educação da Universidade Federal Fluminense. Supervisora educacional da rede municipal de educação de Niterói.

["] Embora oficial, a grafia Paraty foi substituída pelos realizadores da FLIP por "Parati", sendo esta última a constar nos cartazes e todo o material publicitário e de divulgação do evento.

[2] Segundo Eagleton, "uma forma diferente de estetização viria saturar toda a cultura do capitalismo tardio, com seu fetichismo do estilo e da superfície, seu culto do hedonismo e da técnica, sua reificação do significante e o deslocamento do significado discursivo por intensidades causais". (1993, p.269)

[3] Organizações Não Governamentais são instituições que disputam fundos públicos, embora de caráter marcadamente privado.

[4] O evento é patrocinado por mais de 17 empresas, de fabricantes de celulares ao capital financeiro $(O$ Globo. Prosa \& Verso., 03/07/2004).

[5] O capital, enquanto movimento de acumulação, só transforma em riqueza aquilo que cumpre as etapas da circulação: investimento, produção pela força de trabalho e comercialização. Somente assim, o dinheiro transforma-se em capital, pois com valor acrescido ao final do processo. É a partir desse movimento que podemos analisar o papel de destaque da publicidade, como elemento criador de uma nova necessidade de consumo: a mercadoria.

[6] Mesmo sendo bastante restrita a parcela da população que faz turismo na pequena Paraty, nos dias da FLIP, as empresas hoteleiras fecharam suas reservas com considerável antecedência, a empresa rodoviária Costa Verde cobrou do trajeto Rio-Paraty o seu maior preço, aspectos dentre outros que nos leva a perceber que houve uma seleção nada velada.

[7] Cabe destacar que há também espaço para o caráter cultural sem antagonismos,uma vez que é nesse campo que esta mercadoria é consumida.

[8] Ao tratar do caráter misterioso que o produto do trabalho assume sob a forma da mercadoria, Marx escreve: "A forma mercadoria e a relação de valor entre os produtos do trabalho, a qual caracteriza essa forma, nada tem a ver com a natureza física desses produtos nem com as relações materiais dela decorrentes. Uma relação social definida, estabelecida entre homens, assume a forma fantasmagórica de relação entre coisas." (1994: 81).

volta 